\title{
Exploration of Tortious on Live Streaming of Video Games
}

\author{
Hanying Zhang \\ School of Public Administration \\ University of Electronic Science and Technology of China \\ Chengdu, China
}

\begin{abstract}
With the growing popularity of the live streaming of video games, the risk of copyright tort implied by it also appears. Unlike games software, the live streaming of video games has its special features on the determination of copyright. It is a re-creation based on the games. The screen from live online games streaming can be qualified as deductive works, and it needs to comply with the requirements of works in the Copyright Law. Therefore, live streaming should have its separate copyright other than that from videogames. Apart from this, the act of live online games streaming can be categorized as "transformational use", and it should be included in the scope of "fair use system" to be protected by related legislation. Only in that way, we can better cope with the current phenomena of live streaming of video games.
\end{abstract}

Keywords-live streaming of video games; copyright; fair use

\section{INTRODUCTION}

With the development of Internet and information technology, the live streaming of video games has gradually become a new type of cultural industry that enlivens in different internet platforms, introducing the rising threats regarding copyrights. In recent years, many copyright disputes concerning live online games have occurred, such as the NetEase and YY disputed the live copyright issue of "Fantasy Westward Journey" in 2017. The copyright infringement and unfair competition dispute appeal case between Shanghai Yao Yu Cultural Media Co. Ltd. v. Guangzhou Betta Network Technology Co. Ltd. have attracted much attention from the public. Also, due to the significant scale of their parent-companies Tencent and Watermelon video, the copyright ownership of online game live video is becoming a hot topic. In today's society where information technology is rapidly developing, the phenomena of live online games broadcast is becoming more and more common, it is even subverting the traditional and becoming a new profession. Thus, the copyright violation issue behind the online game live broadcast needs to be solved urgently.

\section{The Definition of The NATURE OF ONLINE GAME LIVE BROADCAST}

Nowadays, the universal categories of online games includes role playing games, educational and puzzle games, card and leisure games and battle games. Live streaming of video games is usually based on large role-playing games such as "Glory of The King", "Westward Journey" and "Jedi Survival". Live broadcast refers to the process in which the anchor broadcasts the game process, carrying out various tasks and activities, displaying game skills, and expressing their comments through the media in real-time. Users can watch, learn, or entertain or whatever they want ${ }^{1}$. Live streaming of video games is a dynamic picture composed of a series of continuous online game pictures, live pictures and commentary sounds. To discuss the copyright issue of online game live broadcast, we first need to define the nature of the online game live screen.

\section{A. The Nature of Online Game Live Screen}

The game screen and the online game live screen are two entirely different concepts. The game screen refers to the dynamic picture that appears with the specific characters, scenes, actions, and music that appear after the online game is running. The online game live screen refers to the dynamic picture that the game anchor provides to the network user through the Internet, recording and explaining the operation of the game character to complete the task or display the operation technology to achieve a certain game purpose.

More specifically, the online game screen allows users to obtain fantastic game experience and an unspecified game result through their own control by presenting a fixed, identical scene and character state. It is expressed as a relatively more flexible game basic setting, and it is developed by online game companies to use game settings based on game screen to attract users to download and use. These are the core component of online games.

On the other hand, the live game screen of the online game is to display the operations and skills of the game characters to the user, and supplemented by the explanation or the real-time operation of the real person. The audience learns the operation skills to better control the game characters and achieve a relatively more specific game result based on a relatively fixed game setting. As a main component of live broadcasting, live game screen aims to provide its users a more vivid gaming experience, and meanwhile enlarging the popularity of the game.

Wang Qian, Research on the Copyright of Live Video Games, Electronic Intellectual Property, No. 2, 2016, p. 28 
without the permission of the game copyright owner, the game streamer broadcasts the dynamic process of playing the game directly to the users on the live broadcast platform. Does its behavior infringe the copyright of the game owner?

This article believes that the live broadcast behavior is in line with the fair use of provisions of the Copyright Law and should not be categorized as infringement of the original work.

According to China's "Copyright Law", appropriate citation from a published work of others is needed in one's work for the purposes of introduction to, or comment on, a work, or demonstration of a point. It also, includes appropriate citing of the published work of others provided through the information network.

Further analyzing the word "appropriate" in the appropriate reference, it should be elaborated as the combination of "appropriate length" and "appropriate purpose". Appropriate length, refers to a reasonable length of published work in a new work, rather than completely or mainly replacing the creation of another person's work. Appropriate purpose means that the purpose of citation of a published work in a new work should be limited to "introduction, commentary and explanation" the original work. The reference of the published work cannot lead to competition between the new work and the original work in the market ${ }^{2}$.Academic community has not reached a consensus on how long should a reasonable length be for the online game live broadcast, but according to common sense analysis, online game live broadcasts are an independent piece from the original game. Although the length of time depends on the skill of the operator and is not controllable, the length of "a game" should be consistent with the "reasonable length" requirement.

Therefore, even if the online game live broadcast uses the original game screen, characters, and even themes, it should be excluded from the infringement because it meets the conditions of "fair use".

\section{TRANSFORMATIONAL USE IN AMERICA}

We can link the issue of copyright infringement of live broadcast with the concept of Transformational Use, which is part of the law adopted by America. The concept of "transformational use" comes from the jurisprudence of the "Campbell case" in the United States. The court holds that if the second use behavior (that is, the live broadcast behavior) is based on or uses the original work but has added new expressions, new meanings or new features, it should be considered as a reasonable use of the purpose or method of conversion of the original work ${ }^{3}$. Bases on this judgment, the U.S, Supreme Court adopted the new concept of transformational use for the first time, defining transformational use as "using works for different purposes or ways, and adding new expressions, new meanings or new

\section{EXCLUSION OF INFRINGEMENT ABOUT ONLINE GAME LIVE BROADCAST}

As mentioned above, the online game live broadcast constitutes a work in the sense of copyright law. Then,

\footnotetext{
Wang Qian, A Course on Intellectual Property Law (Sixth Edition), Renmin University of China Press, Sixth Edition, January 2019 See Campbell v. Acuff-Rose Music,Inc., 510 U.S. 569 (1994), p.
} 
functions to the original works" ${ }^{4}$. This judicial precedent cleared the obstacles of the identification and discrimination of the new works produced by the second use of the original works in the United States and made great progress for the system of copyright law.

We can divide the specific performance of transformational use is divided into two types: the using behavior of conversion content and conversion purpose. The using behavior of conversion content, is that, as long as the expression of the original work differently way in the new work, it can be considered as adding new expressions, new meanings or new functions, thereby complying with the requirements for the use of the conversion content. The meaning of the using behavior of conversion purposes and the judicial determination are controversial even in the United States. The mainstream view is that the using behavior of conversion purpose refers to only change the using purpose without changing the expression of the original work.

Because the live webcast works add the game streamers' explanations and operational behaviors on the basis of original works, it is thus different from the original works content - the subjective will, thought, and expressions of the game streamer, constitute new originality. As discussed above, the purpose of online game live broadcast is obviously different from the original game, which does not have the purpose of guiding the user to download and use the original game, but to get a better game experience. Therefore, the online game live broadcast belongs to the category of using behavior for conversion content, and thus conforms to the constituent elements of the transformational use Live broadcast belongs to the transformational use of the original work, and should not be defined as copyright infringement.

\section{THE RELATIONSHIP BETWEEN TRANSFORMATIONAL USE AND "APPROPRIATE CITATION" IN CHINESE LAW}

In China, Transformational Use is only a theoretical principle. In the court case, the concept of "transformation use" cannot be directly quoted. However, according to the provision of Appropriate Citation of Work in China's Copyright Law 22, paragraph 2, and combine it with the requirements and conditions for the transformational use, we can see the similarity between the using behavior of conversion content and the appropriate citation provisions in China's Copyright Law.

First of all, both two are restrictions on copyright infringement of the original copyright owner. Secondly, the two hold the same attitude that the new work is derived from the original works. And both two believe that the new works containing the original works do not necessarily constitute infringement. Finally, according to either the "transformational use" of the United States or the "appropriate citation" of China, the published works cannot be the main part of the new work. The new work should be a re-creation and have its new originality after being modified,

Xiong Qi, Interpretation of the local law of copyright conversion use [J]. Jurist, 2019 (02): 124-134+195. or add new ideas and the proportion of the original work in the new work must be far less than the unique new expression of the inductor's addition to commenting or explaining the original work. In general, both the legislative purpose of the " transformational use" of the United States and the "appropriate citation" standard of China are allow proper usage and creation of the original work, to prevent the copyright owner from being an absolute monopoly on the work, reduce the infringement risk of creators, and to encourage creation from the society. Thus, although China does not formally introduce the concept of "transformational use", the two are consistent with each other in terms of legislative purpose.

Therefore, for the ultimate legislative goal of the Copyright Law, when determining the live broadcast behavior of online games, the concept of "transformational use" should be included in the "appropriate citation" stipulated in Article 22, paragraph 2 of the Copyright Law in China. In that way, we can exclude the online game live broadcast from the infringement due to the evaluation of reasonable usage of original work, and thus promote the prosperity and development of the literary and artistic undertakings.

\section{CONCLUSION}

The online game live broadcast belongs to the adapted works in the deductive works, which conforms to the constituent elements of "work" and should be protected by the Copyright Law. Although China does not stipulate the case of "transformational use", online game live work meets the "transformational use" standard, which is to s protect the interest of the public, and it should not be directly identified as copyright infringement of the original game. Otherwise, it will lead to the rigidity of the literary market and the enthusiasm of social public creation. In view of the provisions of "appropriate citation" in Article 22, paragraph 2 of the Copyright Law of China, the online game live broadcast can be included in this type for consideration, so as to fully protect the performers' copyright of the deductive works, preventing the original copyright owner from monopolizing his works, as well as meet the legislative purpose. All in all, it is conducive to creating a good creative atmosphere for the society.

\section{REFERENCES}

[1] Wang Qian, Research on the Copyright of Live Video Games, Electronic Intellectual Property, No. 2, 2016, p. 28.

[2] Wang Qian, A Course on Intellectual Property Law (Sixth Edition), Renmin University of China Press, Sixth Edition, January 2019.

[3] See Campbell v. Acuff-Rose Music,Inc., 510 U.S. 569 (1994), p. 579.

[4] Xiong Qi, Interpretation of the local law of copyright conversion use [J]. Jurist, 2019 (02): 124-134+195.

[5] Jiao Heping.Re-study on the works attributes of online games online games[J]. Contemporary Jurisprudence,2018,32(05):77-88.

[6] Sun Song. On copyright infringement properties of online game live broadcast [ J] . China Publishing, 2018(21): 37-40.

[7] Kongsi. On the copyright of live online games [J]. Journal of Henan Institute of Engineering (Social Science Edition), 2018, 33(04): 37-39 +72 . 
[8] Lixiaoyu.cognition of copyright infringement in live online games, China Copyright, 2017 No. 1, P. 28.

[9] Zhouhe. American Transformational Use Transformation and Reference to China [J]. Press, 2019(04): 74-84.

[10] Chenguan. Research on copyright issues of online game live broadcast [J]. Legal Expo, 2019(12): 192. 